\title{
INTRODUCTION \\ Radiosurgery and radiotherapy for meningiomas: overview of the issue
}

\author{
Michael W. McDermott, MD, ${ }^{1}$ Jason Sheehan, MD, PhD, ${ }^{2}$ and Steve Braunstein, MD, $\mathrm{PhD}{ }^{3}$ \\ ${ }^{1}$ Department of Neurosurgery, University of California, San Francisco, California; ${ }^{2}$ Department of Neurosurgery, University of \\ Virginia, Charlottesville, Virginia; and ${ }^{3}$ Department of Radiation Oncology, University of California, San Francisco, California
}

$\mathrm{M}$ ENINGIOMAS have been a frustrating tumor for neurosurgeons for more than 80 years, when Cushing published his now-famous book in 1938 with Louise Eisenhardt. ${ }^{1} \mathrm{He}$ said then that "the ultimate prognosis hinges more on the surgeon's wide experience with the problem in all its many aspects...." Such sentiment is so true and fitting that this issue explores the results of radiosurgery and radiotherapy for meningiomas as an adjunct when resection is not sufficient to meet a patient's needs.

Many neurosurgeons believe that radiosurgery is the only type of ionizing radiation with application to the problem of meningiomas. However, the papers by Reddy et al., Alhourani et al., and Yolcu et al. showcase large data sets to document the safety, efficacy, and side effects of fractionated radiation treatment. The readers should be aware of other published papers recently addressing the issue of conventionally fractionated radiation treatment for atypical meningiomas in a prospective trial. ${ }^{4}$

The report by Dawley et al. on complications in 2 patients after radiotherapy highlights the issues of targeting and dose for grade 2 meningiomas. The exceedingly rare subsequent occurrence of a malignant tumor is also presented. The increasing use of dynamic MRI imaging and DOTATOC PET/MRI for targeting is addressed by Chidambaram et al. and Acker et al.

Radiosurgery, delivered on a variety of platforms, is the neurosurgeon's usual go-to procedure when discussing radiation for meningiomas. Fatima et al., Ge et al., and Joshi et al. discuss comparisons between single and hypofractionated stereotactic radiosurgery using the Gamma Knife. While the previously mentioned studies examine the use of photons, Wu et al. review the literature on particle-based treatment results.
Our aim was that neurosurgeons and radiation oncologists be aware of safe and effective treatment methods in the adjuvant setting and for recurrence when considering the risk profile of reoperation in either cranial vault or skull base locations. ${ }^{2,3}$ We attest that this issue accomplishes these goals.

https://thejns.org/doi/abs/10.3171/2019.3.FOCUS19260

\section{References}

1. Cushing H, Eisenhardt L: Meningiomas. Springfield, IL: Charles C. Thomas, 1938

2. Magill ST, Dalle Ore CL, Diaz MA, Jalili DD, Raleigh DR, Aghi MK, et al: Surgical outcomes after reoperation for recurrent non-skull base meningiomas. J Neurosurg [epub ahead of print November 30, 2018. DOI: 10.3171/2018.6.JNS18118]

3. Magill ST, Lee DS, Yen AJ, Lucas CG, Raleigh DR, Aghi MK, et al: Surgical outcomes after reoperation for recurrent skull base meningiomas. J Neurosurg 130:876-883, 2019

4. Rogers L, Zhang P, Vogelbaum MA, Perry A, Ashby LS, Modi JM, et al: Intermediate-risk meningioma: initial outcomes from NRG Oncology RTOG 0539. J Neurosurg 129:35-47, 2018

\section{Disclosures}

The authors report no conflict of interest.

\section{Correspondence}

Michael W. McDermott: mike.mcdermott@ucsf.edu. 